\title{
Impacted bone fragment in a small-bowel diverticulum: an extremely rare cause of obscure gastrointestinal bleeding
}

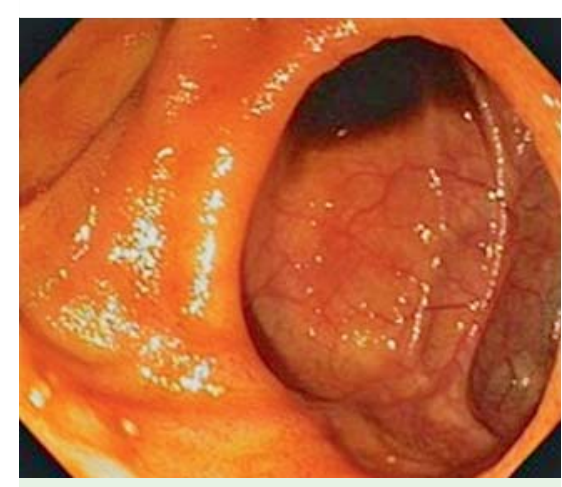

Fig. 1 Large-mouthed small-bowel diverticulum.

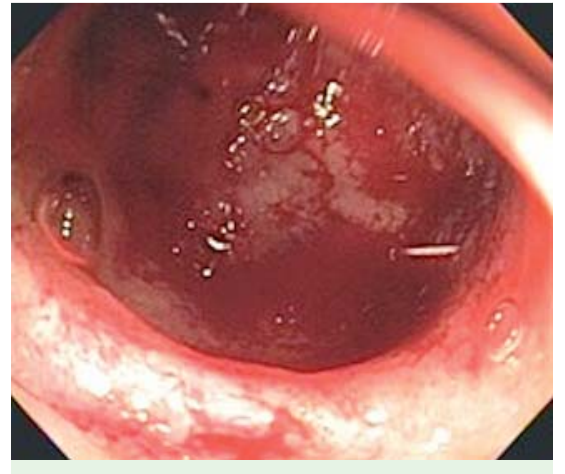

Fig. 2 Evidence of bleeding in a small-bowel diverticulum.
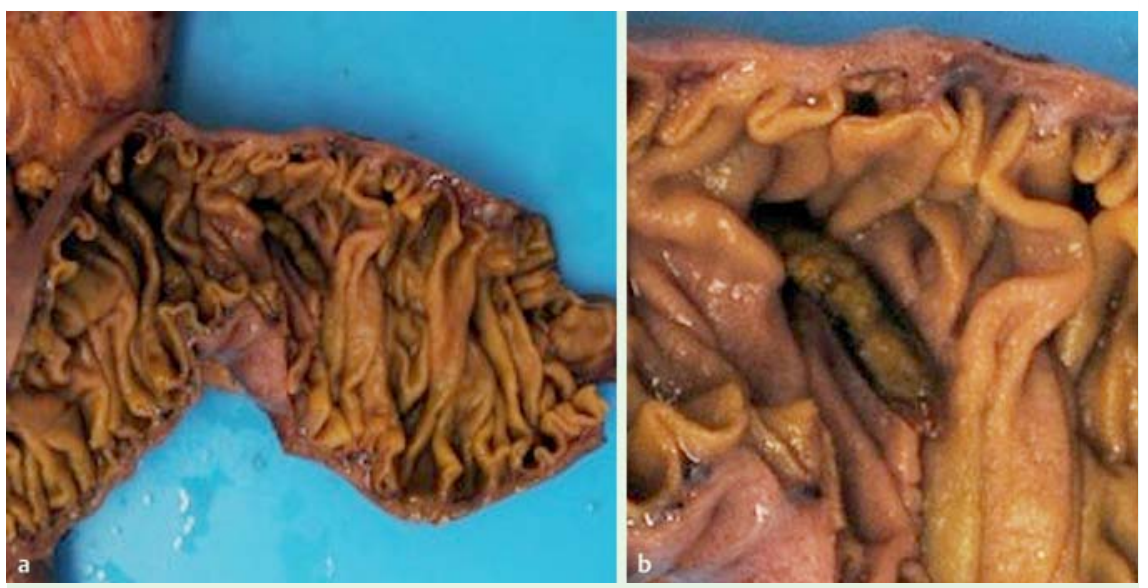

Fig. 3 a, b Small-bowel diverticulum with impacted bone fragment.

Obscure gastrointestinal tract bleeding (OGIB) is a common and challenging issue [1]. Here we present an extremely rare case of overt OGIB secondary to impacted bone fragment within a small-bowel diverticulum.

An 88-year-old man presented with hypotension and a 2-day history of marooncolored stools. Initial hemoglobin concentration was $7.7 \mathrm{~g} / \mathrm{dL}$. Urgent upper endoscopy showed a large duodenal diverticulum with no signs of bleeding. Colonoscopy was also unremarkable. Capsule small-bowel study was attempted, but the capsule was retained in the duodenal diverticulum, requiring endoscopic retrieval. Mesenteric angiography was negative. Delayed images on Tc-99m-labeled red blood cell scan showed activity in the small bowel. Antegrade and retrograde single-balloon enteroscopy to the distal jejunum and proximal ileum showed large-mouthed diverticula but no signs of active bleeding. Intraoperative enteroscopy showed a segment in the mid-small bowel with multiple large-mouthed diverticula, including one diverticulum with a blood clot suggestive of recent bleeding ( Fig. 1, Fig.2). Segmental resection of this small-bowel segment containing the bleeding diverticulum and surrounding large-mouthed diverticula (approx. $60 \mathrm{~cm}$ ) was performed. Postoperatively, the patient's hemoglobin levels remained stable with no further episodes of gastrointestinal bleeding. Examination of the resected small-bowel specimen showed large diverticula with a single diverticulum having an impacted 3-cm bone fragment with hemorrhagic changes in the surrounding mucosa (๑ Fig. 3).

Most of the cases of OGIB are due to smallbowel pathology. Identifying and treating the etiology of OGIB can be challenging [2]. There are only few case reports of foreign body ingestion causing OGIB. Our case is the first report of a bone fragment causing OGIB $[3,4]$.

Endoscopy_UCTN_Code_CCL_1AC_2AH

\section{Competing interests: None}

Hazem T. Hammad', Leen Al-Sayyed', Shoba Theivanayagam', Van Nguyen², Arthur Rawlings ${ }^{3}$, Matthew L.

\section{Bechtold ${ }^{1}$}

${ }^{1}$ Division of Gastroenterology,

University of Missouri School of Medicine, Columbia, Missouri, USA

${ }^{2}$ Department of Pathology and Anatomical Sciences, University of Missouri School of Medicine, Columbia, Missouri, USA

${ }^{3}$ Department of Surgery, University of Missouri School of Medicine, Columbia, Missouri, USA

\section{References}

1 Singh A, Baptista V, Stoicov C et al. Evaluation of small bowel bleeding. Curr Opin Gastroenterol 2013; 29: 119-124

2 Raju GS, Gerson L, Das A et al. American Gastroenterological Association (AGA) Institute technical review on obscure gastrointestinal bleeding. Gastroenterology 2007; 133: 1697-717

3 Samyn I, Reynaert H, Op de Beeck B et al. Recurrent gastrointestinal blood loss of obscure origin: report of an exceptional case. Acta Gastroenterol Belg 1998; 61: 382-384

4 Nanavati SA, Opekun AR, Hacken-Bitar JB et al. Migrating shell fragment as a cause of recurrent obscure gastrointestinal bleeding. J Clin Gastroenterol 2004; 38: 137-138

\section{Bibliography}

Dol http://dx.doi.org/

10.1055/s-0034-1365430

Endoscopy 2014; 46: E262

(c) Georg Thieme Verlag KG

Stuttgart · New York

ISSN 0013-726X

\section{Corresponding author}

\section{Hazem Hammad, MD}

Division of Gastroenterology

Five Hospital Drive

Columbia, MO 65212

United States of America

Fax: +1-573-884-4595

hammadh@health.missouri.edu 